\title{
Movimientos sociales de mujeres en el conflicto armado colombiano: política participativa y periodismo. Reflexiones en torno al caso de las Madres de la Candelaria
}

\section{Social movements of women in Colombian armed conflict: journalism and participatory politics. Reflections on the case of the Madres de la Candelaria}

\author{
Alba Shirley Tamayo Arango \\ Universidad de Medellín \\ astamayo@udem.edu.com
}

\begin{abstract}
Resumen
El texto aborda la relación entre el ejercicio del periodismo y la participación política ciudadana de las mujeres pertenecientes al movimiento social Madres de la Candelaria, de Medellín-Colombia. Mediante acciones colectivas el movimiento social ha logrado visibilizar las víctimas del conflicto armado e incidir en las políticas públicas en relación al tema de la desaparición forzada en Colombia. Todo esto se vincula de manera directa con el trabajo periodístico y con el compromiso social de los profesionales de la comunicación.
\end{abstract}

Palabras Clave: Conflicto armado, mujeres, periodismo, política, acción colectiva.

\begin{abstract}
The text addresses the relationship between journalism and citizen political participation of women belonging to the social movement Madres de la Candelaria, Medellin-Colombia. Through collective actions, this social movement has made visible the victims of armed conflict and has had influence over the creation of public policies on the issue of forced disappearances in Colombia. All this is linked directly with the work of journalists and social commitment of the communication professionals.
\end{abstract}

Keywords: Armed conflict, women, public journalism, collective action. 


\section{INTRODUCCIÓN}

Esta aproximación a las relaciones entre movimientos sociales y ejercicio periodístico parte de la consonancia con la afirmación de Jesús Martín Barbero respecto a que los "desplazamientos con que se buscará rehacer conceptual y metodológicamente el campo de la comunicación vendrán del ámbito de los movimientos sociales y de las nuevas dinámicas culturales, abriendo así la investigación a las transformaciones de la experiencia social" (Barbero, 1993, p. 59).

Lo anterior es claro, toda vez que las demandas de la población, tanto tiempo silenciadas por el ejercicio periodístico que cohonesta con la hegemonía instaurada por las minorías más poderosas, emergen en el mundo contemporáneo con una potencia difícil de ocultar, orientando la praxis comunicativa hacia derroteros más participativos e incluyentes. Un aspecto relevante es que la democratización de los medios es forzada por el poder del número, que hace de los movimientos sociales actores válidos y visibles, con los que es obligado interlocutar sobre experiencias sociales colectivas capaces de poner de manifiesto las posibilidades de transformación social.

En este sentido, entender las nuevas manifestaciones colectivas dentro de la actual sociedad post-industrial globalizada (Garretón, 1998), implica ubicarse dentro de un universo donde la comunicación se constituye en factor estructurante de organización social, ya que a diferencia de lo que ocurría en la época de la sociedad industrial, ahora "el lugar de encuentro de la gente no es la fábrica ni el partido ni la asamblea, son los «mail» y el espacio público creado por los medios de comunicación de masas" (Garretón, 1998, p. 3). Este escenario implica que la comunicación sea determinante para cualquier movimiento social, en tanto que la incidencia de "los medios de difusión masiva se ha vuelto cada vez más crucial a la hora de conformar representaciones, imágenes y discursos sobre los movimientos sociales, incluso para el interior de los mismos movimientos" (Rovira-Sancho, 2013, p. 37).

La visibilidad social, lograda a través de los medios, va a ser fundamental entonces para que los movimientos sociales consigan que las problemáticas por las cuales se movilizan sean reconocidas y legitimadas por la gente. De ahí el poder simbólico que ejercen los medios mediante la generación de opinión pública. Pues hay que tener en cuenta que el poder de los medios radica en la orientación de las interpretaciones de la realidad, a la vez que generan una visión sobre ella, más o menos crítica según los intereses económicos o políticos, los cuales determinan muchas veces la posibilidad de hablar sobre unos u otros temas y silenciar u ocultar hechos.

Este es el caso de la desaparición forzada en Colombia. Aunque en la actualidad es un tema que forma parte de la agenda política, ha habido un largo silencio y un desconocimiento público sobre su ocurrencia y sus repercusiones. Es solo a partir de 2007 que el gobierno comenzó a darle visibilidad oficial al fenómeno, al generar 
procesos más claros de registro bajo la voluntad de establecer estadísticas lo más ajustadas posible a la realidad. Si bien este rigor hace que los datos se incrementen día a día, lo cierto es que las cifras siguen sin conseguir correspondencia precisa con los hechos, pues los subregistros son bastante comunes a raíz de la carencia de denuncia por cuenta del miedo instaurado como consecuencia de las retaliaciones y las amenazas.

Este interés por un tema que saca a la luz la violación de los Derechos Humanos en el país surge, en buena medida, por la visibilización mediática, resultado de la presión ejercida por los movimientos sociales a lo largo de los últimos quince años. Entre ellos, los más destacados son los movimientos de víctimas constituidos por familiares de personas desaparecidas. La labor de visibilización no ha sido fácil, pues si miramos hacia atrás hay que poner de manifiesto la habilidad del gobierno para proyectar una imagen de éxito respecto al conflicto, lo que "también ha contribuido para que las desapariciones, junto con otros abusos de derechos humanos, sean menos visibles. El hecho de que el conflicto siga activo dificulta prestarle atención a un crimen donde las pruebas son invisibles por definición” (Haugaard y Nicholls, 2010, p. 3). Por otra parte, es necesario recordar que las estrategias de terror por parte de los victimarios siguen constituyéndose en uno de los pilares para conseguir el ocultamiento de los hechos atroces, y el periodismo es también víctima de ello.

Sin embargo, el eco de estas luchas en los medios masivos de comunicación del país ha ampliado el rango de posibilidades para quienes no han tenido, en el marco del derecho real, derechos, sino más bien han estado marcados por la desigualdad constitutiva. Es así como las mujeres han abierto nuevos espacios de participación cultural, social y política en Colombia a través de acciones colectivas visibles. Mujeres que, como las integrantes de la Asociación Caminos de Esperanza Madres de la Candelaria, han sufrido las consecuencias del conflicto armado de modo directo e indirecto. Estas mujeres presionan para que la vulneración de sus derechos no forme parte de lo que se ha dado en llamar, dentro dellenguaje periodístico, "hechos aislados", sino que se trate como acontecimientos imbricados en una cultura de violencia que recae sobre personas marginales, débiles, desiguales o diferentes.

La puesta en escena pública del tema de la desaparición forzada es una cuestión de compromiso con la búsqueda de soluciones al conflicto armado. Las innumerables consecuencias que ha generado en la sociedad es un terreno aún por explorar, pues hay una labor de memoria histórica por hacer, y esto solo es posible en la medida en que el ejercicio periodístico se decante por presentar todas las aristas de la realidad, los actores con sus condiciones y sus experiencias, en lugar de dejarse llevar por la simplificación informativa.

En este orden de ideas, los escalofriantes datos respecto a la desaparición en Colombia se constituyen en realidad inocultable. El Informe del Centro Nacional de Memoria Histórica (CNMH) de 2013 afirma al respecto que: 
el Registro Nacional de Desaparecidos reportó, hasta noviembre del 2011, 50.891 casos, de los cuales se presume que 16.907 corresponden a desapariciones forzadas, mientras que el ruv ${ }^{1}$ registra 25.007 personas desaparecidas forzosamente como producto del conflicto armado. Esta elevada magnitud solo puede comprenderse cuando se constata que tal delito rebasa lo ocurrido en las dictaduras militares del cono sur de América Latina: 485 desapariciones forzadas en Paraguay entre 1958 y 1988; 979 en Chile entre 1973 y 1990; y cerca de 9.000 en Argentina durante la dictadura militar entre 1976 y 1983. Pese a las dimensiones de la desaparición forzada en Colombia, el nivel de reconocimiento social y público de este delito es muy bajo si se lo compara con otras modalidades de violencia (CNMH, 2013, p. 58).

En estas circunstancias, la lucha de los movimientos sociales, en nuestro caso de la Asociación Caminos de Esperanza Madres de la Candelaria, se ha encaminado hacia el reconocimiento público de la desaparición forzada como hecho ominoso que conlleva profundas repercusiones sociales, pues se trata de una práctica vinculada al destierro, la persecución, la viudez, la orfandad y la pobreza. El trabajo colectivo de estas mujeres-madres se orienta entonces en contra de la inexistencia política en Colombia de estos hechos atroces. Las demandas populares exigen así un periodismo comprometido con la puesta en escena pública de temas ocultos por mucho tiempo. Es decir, se demanda un periodismo público, que:

se articula en torno al concepto de opinión pública a partir de tres pilares básicos para la cultura democrática: el debate público, la deliberación y la participación del ciudadano del común en los debates sobre el interés público. El Periodismo Público se inscribe pues en una de las dos lógicas centrales identificadas en la literatura especializada: la opinión pública como debate público. La otra lógica es la de la opinión pública como control social (Miralles, 2009, p. 43).

En consecuencia, este artículo se propone hacer una reflexión sucinta sobre la relación entre el ejercicio del periodismo en diferentes medios de comunicación y las nuevas formas de ejercicio político desde una de las poblaciones más golpeadas en Colombia por el conflicto armado: la población desplazada víctima de la desaparición forzada, cuyas acciones colectivas se caracterizan por ser lideradas e integradas en su mayoría por mujeres campesinas. Para ello, nuestro interés se centra en los procesos y condiciones que llevan al reconocimiento y visibilidad social de las víctimas y de sus demandas, lograda por la Asociación Caminos de Esperanza Madres de la Candelaria, y en los que están implicados los medios locales, nacionales e internacionales, alternativos y masivos.

1 RUV: Registro Único de Vivienda. 


\section{LAS MADRES DE LA CANDELARIA: VISIBILIZANDO LA DESAPARICIÓN FORZADA}

Las Madres de la Candelaria, se denomina, de manera coloquial, al grupo de mujeres que desde hace 14 años se reúne todos los viernes a las dos de la tarde frente al atrio de la emblemática iglesia de Nuestra Señora de la Candelaria, en la ciudad de Medellín, para reclamar al Estado colombiano justicia y verdad sobre el paradero de sus familiares, desaparecidos por distintos actores armados: guerrilla, paramilitares o fuerza pública, a pesar de no estar involucrados con el conflicto. Su presencia allí comenzó por comunicar al país la necesidad de sumar a las mujeres a la categoría de víctimas de la guerra, pues sufrían las consecuencias de acciones atroces sobre sus seres queridos, algunos de ellos menores de edad, desaparecidos en medio de hechos ominosos como masacres, muertes selectivas, violaciones, desplazamientos y destierros.

Hasta su pertenencia al movimiento, las mujeres habían vivido de manera individual la desaparición forzada y sus efectos adversos sobre la propia vida. La acción de la violencia continua y vivida en diferentes escenarios y versiones hace que los desplazamientos muchas veces sean múltiples, lo cual va conduciendo a las víctimas por un sendero cada vez más cerrado, parapetado en la sobrevivencia, cuando no en la pobreza extrema y la miseria, asumida como única opción de vida en las grandes ciudades como Medellín. Frente a este panorama, la integración a la acción colectiva, bajo la identificación oficial de Asociación Caminos de Esperanza Madres de la Candelaria, ha logrado que las mujeres, en su mayoría campesinas llegadas a la ciudad de manera forzada, buena parte de ellas solas y con hijos o nietos a su cargo, salgan de los laberintos del trauma y el duelo, para trazar juntas nuevas razones de lucha y de vida. La solidaridad como principio fundante mantiene hasta la actualidad la cohesión de quienes enfrentan unidas el dolor de la ausencia sin fin y unidas lo dan a conocer a la sociedad.

Es así como a lo largo de este tiempo, en el que no ha cesado el conflicto, al movimiento de las Madres de la Candelaria se siguen sumando cada día nuevas integrantes. En la actualidad el movimiento cuenta con 886 familiares de personas desaparecidas o secuestradas, $92 \%$ mujeres y $8 \%$ hombres, procedentes de diversas zonas de conflicto dentro del territorio nacional, pero sobre todo de las principales zonas del departamento de Antioquia, como el oriente antioqueño, las regiones de Urabá, Bajo Cauca, nordeste y suroeste.El plantón, como se le denomina a la acción semanal en el atrio de la iglesia de La Candelaria, se realizó por primera vez el 19 de marzo de 1999 por un grupo de 14 mujeres, lideradas por Teresita Gaviria Urrego víctima de la acción paramilitar a causa de la desaparición de su hijo de 15 años-.Allí, con las fotos de sus dolientes en el pecho (replicando la experiencia de las Madres de la Plaza de Mayo en Argentina), se desmarcaban de los familiares de sujetos vinculados 
al conflicto armado como actores directos: policías y militares secuestrados o desaparecidos, congregados en la Asociación Colombiana de Familiares de Miembros de la Fuerza Pública Retenidos y Liberados por Grupos Guerrilleros (Asfamipaz).

Esta acción colectiva en el atrio se ha vinculado con otras actividades que atienden al objetivo de hacer saber, crear conciencia y despertar sensibilidad respecto de la desaparición forzada como realidad que poco a poco ha dejado de ser invisible para buena parte del país. Desde los inicios del movimiento, la líder Teresita Gaviria Urrego, se dio a la tarea de visitar a los funcionarios de la Gobernación de Antioquia y de la Alcaldía de Medellín para conseguir adhesión y apoyo, bajo la certeza de que la comunicación directa resultaría de suma efectividad para generar interés por un problema que no era individual sino social. Ella tenía la seguridad de que el posicionamiento del movimiento se lograría con el paso del tiempo. Lo constata en la actualidad, después de 14 años de lucha, cuando todavía recuerda que su propósito era la sensibilización, visitando las instituciones con insistencia a través de:

unos mensajitos. No estaba de tanta moda el internet, y éramos unas papas completas con el internet $-\mathrm{y}$ somos todavía-, entonces mandaba unos mensajitos y decía: «nosotras somos víctimas de la desaparición forzada, somos víctimas del desplazamiento, eh.. Somos víctimas de masacre y no queremos que a usted le ocurra lo mismo. ¡Apóyenos!» Entonces los metíamos por debajo de las puertas y eso era contundente para todo el mundo. Yo iba a la Alcaldía de Medellín, y... ¿Usted a qué viene? $[\ldots]$ Mirá, tenemos los familiares desaparecidos, entonces por eso nosotros existimos. Y queremos posicionar en Medellín ese movimiento de víctimas, que somos muchas víctimas en el país. Entonces me iban grabando, me iban grabando y eso se iba transmitiendo a los medios de comunicación. Los medios de comunicación no querían saber nada de nosotras al principio... (Gaviria, entrevista, 2013).

Este no querer saber que relata Teresita Gaviria se vincula con el estigma que han cargado en Colombia las víctimas del conflicto armado. A ellas se les atribuye alguna razón que explica lo que han sufrido, esa razón se enlaza con su pertenencia a cualquier ala del conflicto, lo cual genera discriminación y rechazo por el miedo a las posibles consecuencias por su cercanía, porque también el señalamiento puede recaer sobre quienes las visibilizan, pues las víctimas muestran en su ser los efectos más devastadores de la guerra, ponen en evidencia los desmanes de los diversos actores y de los intereses que los mueven.

Entonces, en este pedregoso recorrido por la legitimación del movimiento social y de sus demandas, encontramos que la jerarquía eclesial es el primer peldaño donde comienza la trayectoria institucional que presta apoyo a la empresa de visibilización del dolor de las Madres de la Candelaria. Las palabras de Teresita Gaviria, líder fundadora dejan constancia de ello: 
le pusimos ese nombre porque, primero: no nos dejaban ubicar en ninguna parte, de todas partes nos echaban porque nos confundían y decían que éramos un objetivo militar y en la única parte que nos recibieron sin humillaciones fue en la Iglesia Nuestra Señora de la Candelaria, por eso lleva su nombre; caminos de esperanza es porque nosotros todos los días estamos en un caminar, en un largo trasegar, buscando los desaparecidos, buscando la verdad y hoy seguimos buscando la reconciliación. La esperanza es porque nunca hemos perdido la esperanza de encontrar todos los desaparecidos en el país, porque nosotras cuando hacemos las pasantías en otros departamentos nos damos cuenta que a las mujeres no les permiten hablar ni contar sus historias, ni sus experiencias, entonces nosotras hemos logrado llegar donde ellas para que por lo menos aprendan a contar sus propias historias (Gaviria, entrevista, 2012).

Es a la luz de la labor de gestionar políticas públicas de atención integral a las víctimas que ha crecido la Asociación Caminos de Esperanza Madres de la Candelaria. En consonancia con otros movimientos sociales, la Asociación ha logrado visibilizar el fenómeno complejo de la desaparición forzada en Colombia, presionar a los entes gubernamentales y generar acciones del gobierno en relación a la reparación integral de las víctimas, al apoyo a su búsqueda de la verdad, a la gestión de programas que propendan por la pazy la reconstrucción de la memoria histórica, con el fin de que los hechos atroces no se repitan. A lo largo de sus 14 años de recorrido la Asociación ha ganado legitimidad frente a los medios de comunicación y los entes estatales, lo cual se refrenda con el Premio Nacional de Paz en 2006, otorgado por Caracol Televisión, El Tiempo Casa Editorial, Proantioquia, Caracol Radio, el Programa de las Naciones Unidas para el Desarrollo (PNUD), la Revista Semana y la Friedrich Ebert Stiftung en Colombia (FESCOL), responsable de la Secretaría Técnica del premio.

El reconocimiento estatal es tangible en el enlace que la Asociación Caminos de Esperanza Madres de la Candelaria realiza en la actualidad entre el gobierno y las víctimas, pues estas últimas no siempre creen en un Estado que, según su experiencia, se destaca por su ausencia y a veces por su agresión directa a través de la policía o las fuerzas militares. Sus actividades de orientación jurídica respaldan la puesta en marcha de la reparación económica dentro del marco de la Ley de Justicia y Paz. De igual manera, hacen posible para las entidades tener la certeza de tratar con verdaderas víctimas.

Aquí es obligado resaltar que en buena medida, la visibilidad pública de las Madres de la Candelaria y su posterior legitimación ante las instituciones deriva del trabajo periodístico. La cobertura de los medios masivos de comunicación desde el plantón hasta las manifestaciones y actos simbólicos en diversos escenarios de la ciudad y del país a lo largo de estos años, ha hecho que las Madres de la Candelaria sean conocidas y reconocidas por su labor en favor de las víctimas, al igual que apreciadas por otras asociaciones y grupos de población victimizada, generando confianza para establecer 
redes de acción. Por otro lado, las entidades gubernamentales reconocen su trabajo y compromiso social, por la polifonía mediática que dejar ver a mujeres que orientan sus labores hacia la reconciliación y la paz.

\section{EL PLANTÓN: ACCIÓN COLECTIVA QUE DEMANDA PERIODISMO PÚBLICO}

El plantón de las Madres, que fue inicialmente todos los miércoles y luego pasó a ser los viernes, es una acción colectiva que se constituyó en estrategia de comunicación con alta efectividad debido a su prolongación en el tiempo, ya que se ha mantenido desde el inicio del movimiento. Su localización, en un lugar cargado de historia y simbologías de poder en el centro de la ciudad de Medellín, responde a una propuesta consciente y racional desde la comunicación, ya que el fin último del movimiento es informar a la sociedad sobre la existencia de las mujeres-madres como víctimas en razón de la desaparición forzada de sus familiares.

IMAGEN 1: Plantón en el atrio de la iglesia de la Candelaria. Septiembre de 2012

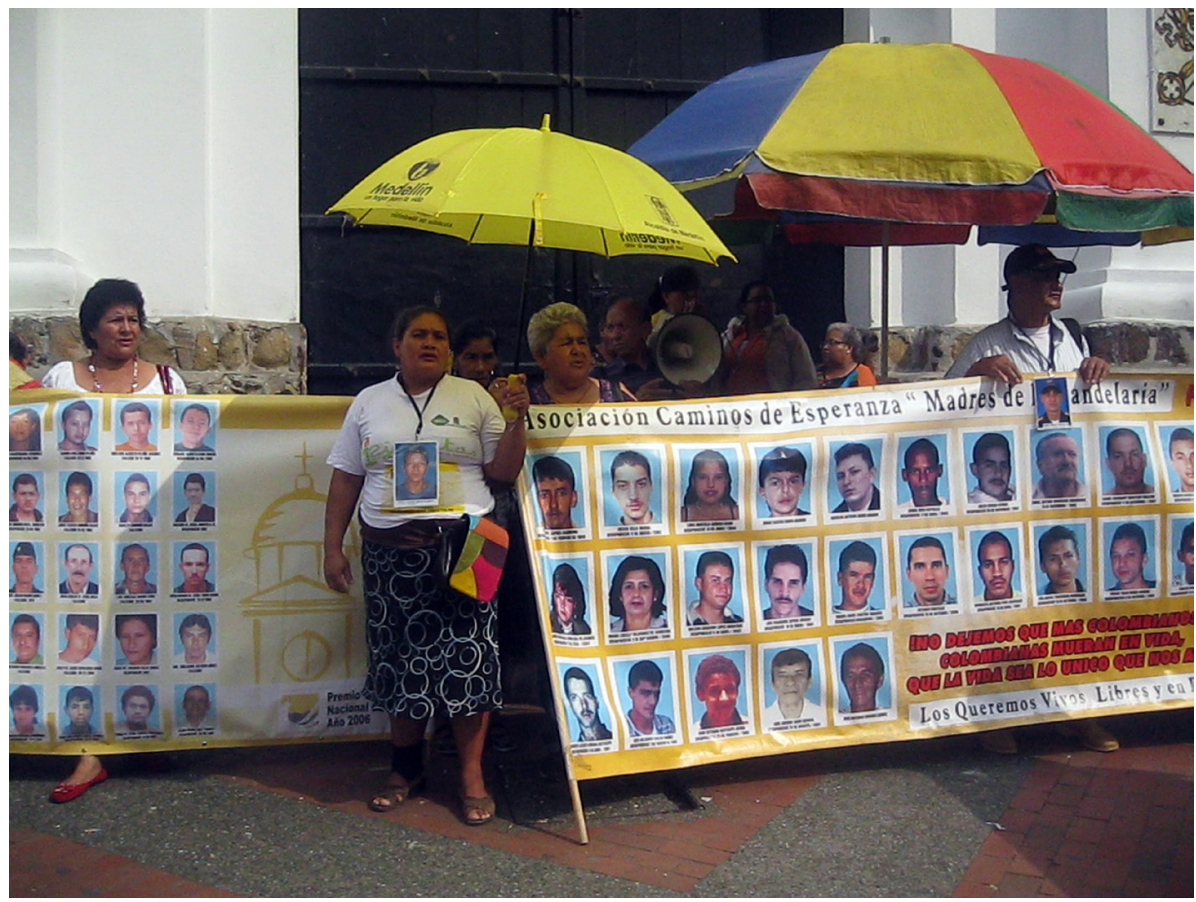

Fotografía: Alba Shirley Tamayo Arango 
Estas acciones colectivas conducen a la construcción de espacios públicos, en el sentido democrático y dialógico del término. Es desde ahí que podemos afirmar que la Asociación Caminos de Esperanza Madres de la Candelaria va a contribuir a generar ciudad, en concordancia con la apuesta de Jordi Borja y Zaida Muxí (2000) de que "la ciudad es la gente en la calle" (p. 13).

Mediante la manifestación semanal con el plantón, la Asociación logra hacer surgir y reforzar la empatía y solidaridad de la ciudadanía con el dolor y la lucha de las Madres. De esta permanencia en un escenario central de la ciudad hacen eco las publicaciones continuas en los medios masivos más poderosos, pero aún más las que son producto del ejercicio del periodismo público o cívico, que rebasa los límites asignados por la agenda señalada desde los entes oficiales, inclinándose hacia los temas de interés público-político (Lecaros, 2003, p. 65).

Las Madres de la Candelaria, aun siendo en su mayoría madres de familia y amas de casa sin altos grados de escolaridad -todavía hay un alto porcentaje de sus integrantes que son analfabetas-, más aún, sin conocimiento técnico ni académico que sustente las actuaciones vinculadas a la comunicación masiva, han logrado que el plantón genere visibilidad pública respecto a los efectos del conflicto sobre la población civil, a través de una comunicación estratégica en el sentido práctico y creativo de la palabra. Desde su practicidad estas mujeres han llevado al hecho la afirmación de que los medios y los comunicadores sociales deben cumplir con la responsabilidad, dentro de un Estado de derecho democrático, de construir lo público, mediante un espacio donde la opinión incluya la multiplicidad de voces que conforman las sociedades plurales, en las que se esgrimen pretensiones de democracias participativas (Hoyos, 2010, p. 54).

En este orden de ideas, la relación entre participación política de la ciudadanía y medios de comunicación puede verse en ese juego de doble vía que se produce entre movimientos sociales y representación social mediática. Es claro que los medios masivos de comunicación legitiman las acciones ciudadanas mediante la publicación de las expresiones de demanda o de gestión, pero también los movimientos sociales legitiman a los medios masivos al proporcionarles contenidos que permiten situarlos del lado de la democracia, dando lugar a la pluralidad, y generando sentido social de lo público. Frente a lo anterior es preciso aclarar que esto ocurre dentro de tensiones e intereses vinculados a la palabra pública, al poder que se tiene sobre ella, pues es bien sabido que el formato de carácter informativo con mayor espacio en los medios es la noticia, y "la naturaleza de las noticias hace que se orienten hacia unos protagonistas que están en alguna posición de poder, y los ciudadanos por lo general juegan el papel de víctimas o de testigos de sucesos que ocupan la atención de los medios" (Miralles, 2002, p. 23).

No obstante, los medios de comunicación de la ciudad de Medellín y en algunas ocasiones los medios nacionales, están al tanto de las acciones de las Madres de la 
Candelaria. En su afán por la espectacularidad de la noticia, los medios locales comenzaron a relacionarse con un movimiento de mujeres potente, que con el correr del tiempo exigiría del ejercicio periodístico su compromiso real con las víctimas, con la reparación, la justicia y la verdad. Esto ha sido posible ya que el movimiento ha sabido abrirse espacio en el mundo de la información mediática, manteniéndose en la agenda periodística, resquebrajando la clásica imagen de la víctima como sujeto pasivo, a través de "una muy buena relación con los medios" (Gaviria, entrevista, 2013), que empezó con Teleantioquia, luego Telemedellín, RCN y Caracol, aunque en esa época (año 2000) eran periodistas extranjeros (argentinos), quienes más se interesaron por su forma de manifestación. Fue así que Teresita Gaviria, en representación del movimiento, conoció a las abuelas de la Plaza de Mayo y empezó una relación que se amplió con "las mujeres del Salvador, ahí empezó con las mujeres del Ecuador... Es decir, tenemos muy buenas relaciones con estas personas, porque nos dijeron: nosotras nos organizamos después del conflicto y ustedes fue dentro del conflicto. Esa es la ventaja de nosotros, por eso este movimiento es muy respetado" (Gaviria, entrevista, 2013).

La persistencia del plantón a través de los años, sus reivindicaciones y su participación activa en la ciudad en relación a la puesta en evidencia de las violaciones de Derechos Humanos, ha propiciado la credibilidad y la confianza como fuentes, permitiéndoles ser gestoras de opinión en representación de las víctimas. El periodista de RCN (Radio Cadena Nacional de Colombia), Juan Carlos Higuita, afirma que durante los años que cubrió noticias en Medellín siempre buscó a Teresita Gaviria, pues para él tiene mayor representación quien ha vivido la experiencia de ser víctima, ya que su voz significa más frente a quien habla desde la abstracción de los hechos (Higuita, entrevista, 2013).

A lo largo de estos 14 años de lucha, las Madres de la Candelaria se han posicionado en los medios de comunicación por su visible participación política en asuntos relativos al conflicto armado. Esta legitimidad y reconocimiento mediático hace que el movimiento sea proveedor de noticias, lo cual las mantiene en la agenda de los medios y les ayuda a conservar su imagen como entidad activa. En este sentido, las fechas especiales, relacionadas con los Derechos Humanos, la memoria histórica del conflicto, o la entrega de cuerpos, se constituyen en noticia para los medios. Sin embargo, prevalece el afán de la visibilidad de lo negativo, las denominadas noticias que venden están relacionadas con el hecho victimizante, pues la noticia "responde a los criterios de notoriedad, de lo inédito, lo impactante, lo espectacular, fuera de lo común, la prominencia y la emoción” (Miralles, 2002, p. 47), cuestiones lejanas de los criterios de lo público, donde los asuntos de interés general son los preponderantes, y estos no necesariamente obedecen al mercado.

El periodista Juan Carlos Higuita, quien las conoce desde sus comienzos, ratifica tanto el efecto mediático de los plantones en el atrio de la iglesia de la Candelaria 
como la vinculación de las Madres a los hechos de gran despliegue informativo en los últimos diez años:

por eso fue que se empezaron a dar a conocer... y se volvían importantes cuando se producían secuestros, cuando habían noticias sobre secuestrados, cuando había noticias sobre procesos de paz, de negociación, en situaciones de rescate, por ejemplo, o en situaciones que involucraban a personas que estaban privadas de la libertad [ ... ] En los procesos de justicia y paz también se volvieron importantes porque muchas de esas personas son víctimas del paramilitarismo en el país, entonces en ese momento también ellas acudían a las versiones libres. Cuando empezaron las versiones libres de los, de los ex jefes paramilitares también se volvieron fuente de consulta para... averiguar si ellas tenían noticias ya de sus seres queridos como tal (Higuita, entrevista, 2013).

\section{IMAGEN 2: Cubrimiento mediático del día del Detenido Desaparecido 30 de agosto de 2012, Parque Bicentenario de la ciudad de Medellín}

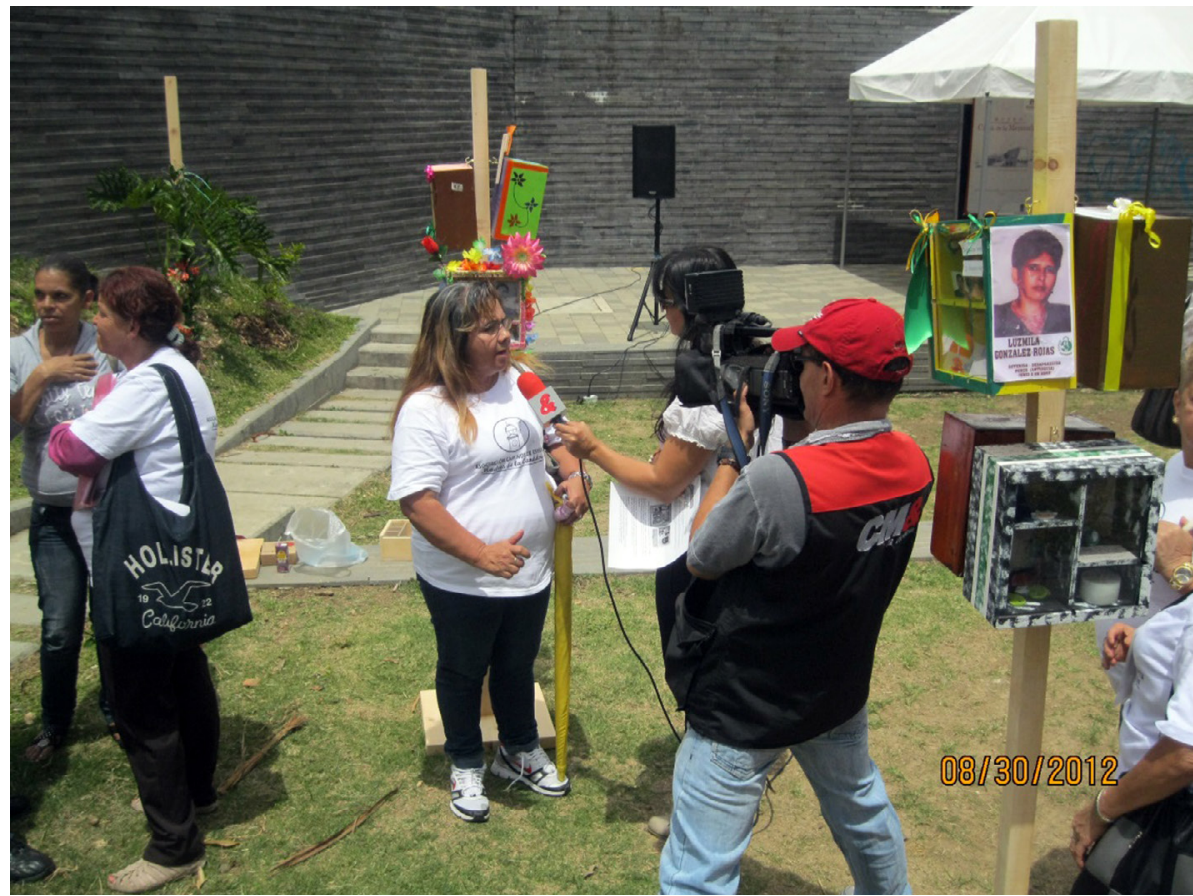

Fotografía: Alba Shirley Tamayo Arango 


\section{IMAGEN 3: Cubrimiento mediático del día del Detenido Desaparecido 30 de agosto de 2012, Parque Bicentenario de la ciudad de Medellín}

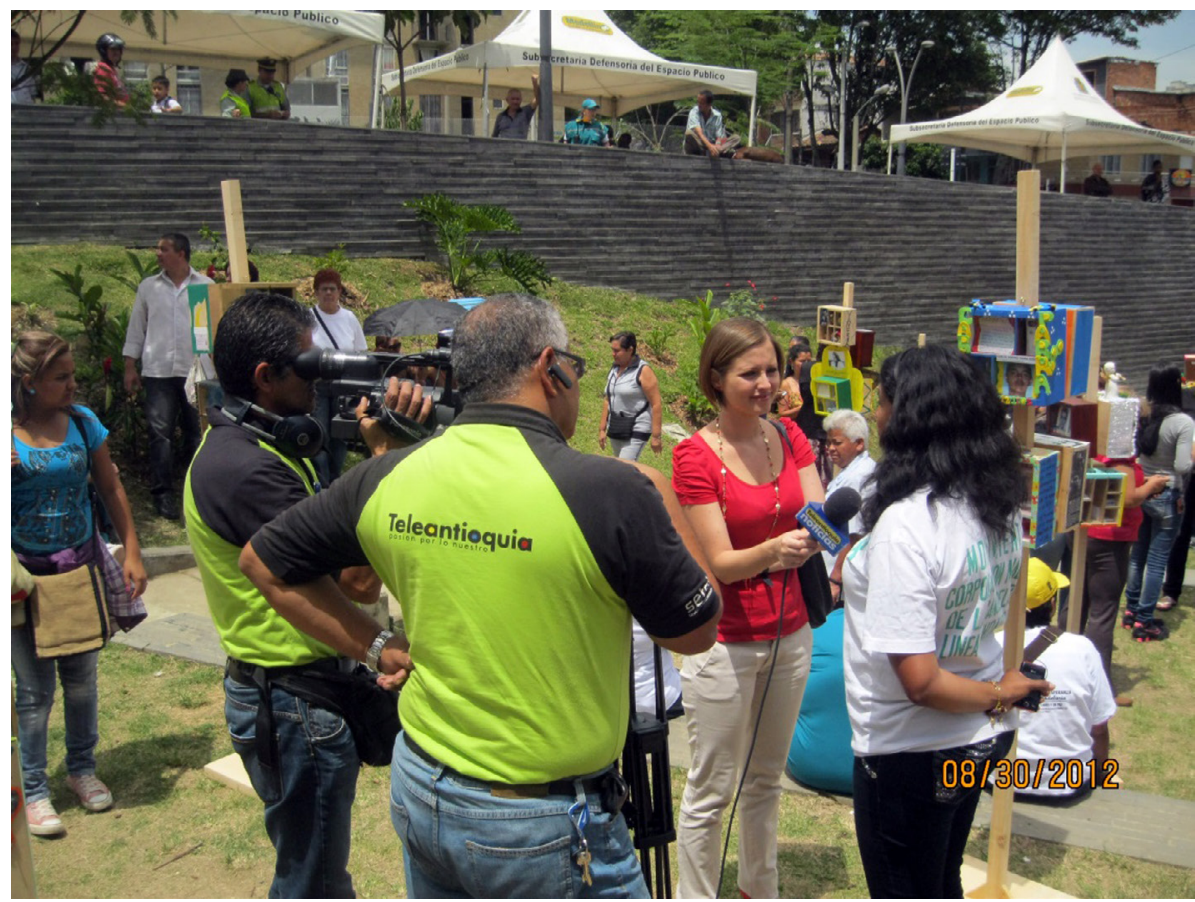

Fotografía: Alba Shirley Tamayo Arango

Sin embargo, la cita en el plantón ha sobrepasado la idea de ser una convocatoria a los grandes medios sólo en tiempos de coyuntura política. El ejercicio del periodismo alternativo y con compromiso social, tanto en pequeños como en medios de gran capital económico, ha redundado en el conocimiento de detalles de esta acción colectiva, como el despliegue de los pasacalles con las fotografías de los familiares desaparecidos, el uso del altavoz y las consignas, que llaman la atención de los transeúntes. Es de anotar que las imágenes, cada una con la fecha de desaparición, narran la larga espera de las mujeres, y remiten a su vez a las épocas de mayor violencia contra la población en el país (años 2003 a 2008). A través de ellas se pueden reconstruir trayectorias temporales y espaciales donde se ha desarrollado el conflicto, dejando como consecuencia la desaparición de civiles.

La esporádica presencia de las Madres de la Candelaria en los medios a través de la noticia, es contrarrestada por la construcción de espacio público mediante la puesta en escena pública de intereses sociales generales como la paz. En este orden de ideas, los medios de comunicación dan lugar a estas nuevas formas de la política a través del diálogo que establecen entre los diferentes formatos, cuando rebasan la mera información noticiosa y amplían las posibilidades de comprensión de la ciudadanía mediante las crónicas, los reportajes o las entrevistas. Estos formatos van entregando 
al público una visión compleja y más completa de los hechos, donde las víctimas se constituyen en actores políticos, ejerciendo nuevas formas de ciudadanía.

Es de resaltar que estas publicaciones son discontinuas y ocasionales, y son posibles por múltiples factores: el compromiso social y ético del(a) periodista; la apertura y flexibilidad de los criterios de los medios masivos; la pertinencia del contenido respecto a la realidad palpable de exigencias de entes internacionales en relación a la protección de los Derechos Humanos; la conveniencia de mostrar acciones políticas de las Madres, así como sus exigencias y propuestas, en razón de la identificación de una buena parte de la población que ha sufrido la guerra. Por otra parte, estas temáticas están a la orden del día en un universo comunicacional marcado por la violencia, el dolor, el sufrimiento, como cuestiones que se venden y se consumen como una mercancía informativa que permite vivir, desde la comodidad de la silla, la espectacularidad de la violencia hacia y contra otros.

\section{IMÁGENES Y REPRESENTACIONES EN LOS MEDIOS}

Siguiendo a María Trunó, afirmamos que las definiciones de víctima desembocan en cuestiones comunes como: "por un lado, la imagen de alguien que ha sufrido daño y lesión por fuerzas fuera de su control: y por el otro, el hecho de que ser víctima se conecta con un estado de debilidad que necesita protección” (Truñó, 2007, p. 136).

Estas características han sido utilizadas por los medios de comunicación masiva para reforzar las representaciones sociales de las víctimas como personas inermes, indefensas, pasivas y entregadas al arbitrio ajeno, porque esa misma debilidad que proviene del prejuicio se hace converger, en último término, en incapacidad. Estas representaciones abundan en los formatos informativos a su vez orientadas hacia las mujeres, seres sobre los que ha recaído de manera histórica el estereotipo del ser necesitado de protección y cuidado. Lo anterior nos lleva a constatar que "la mirada victimista es reduccionista y reproductora de la mentalidad que subyace en el victimario” (Magallón, citada por Truñó, 2007, p. 136).

Estos ejercicios de poder sitúan a las víctimas en el individualismo que no construye ciudadanía, pero la mirada de las propias víctimas organizadas muestra que luchan por cambiar su vida y transformar su trauma en herramienta de acción social. El caso de las Madres de la Candelaria evidencia que las mujeres víctimas del conflicto armado se destacan por su capacidad de resiliencia y de lucha. Los medios locales han hecho eco de esta potencia de lo colectivo con marca femenina a través de la legitimación de sus demandas y la puesta en valor de sus manifestaciones. Esto contribuye a la generación de una representación de las mujeres-madres víctimas que rompe con los esquemas establecidos, que es leída por las instituciones públicas. La directora de la Unidad Municipal de Atención y Reparación a Víctimas, Luz Patria 
Correa, por su contacto diario con las organizaciones de mujeres que llegan a su despacho, analiza que frente al hecho victimizante, las mujeres tienen, en términos psicológicos, más fuerza ante la adversidad:

ellas encuentran, aún en medio del conflicto y todo lo que les sucede, formas de hacerle frente, en razón de sus hijos... y los hombres se quiebran más emocionalmente, entonces ellos pierden casi que el papel protagónico $[\ldots]$ las organizaciones de ellos son puestas desde ese lugar, desde el lugar del poder que en algún momento tuvieron (Correa, entrevista, 2013).

De otro lado, es de resaltar que la presencia de las madres en el atrio de la iglesia de la Candelaria está cargada de una simbología de desafío a los actores armados, pues se trata de una acción colectiva permanente que se lleva a cabo en medio del conflicto. En relación a esto hay que contar con el hecho de que "en la vida cotidiana de la ciudad de Medellín, las violencias y el terror son realidades tangibles: pueden ser contadas - como en el número de los muertos-, experimentadas -como en la imposibilidad de circular por ciertos territorios-, o sentidas -como en las heridas que marcan los cuerpos de hombres y mujeres-” (Riaño, 2002, p. 85).

Esta persistencia y tenacidad de las mujeres del movimiento puede constatarse siguiendo el histórico de la cobertura que han hecho los medios. Pero también, la información de los medios masivos de comunicación ha mostrado la cara dura del desafío que significa exigir la verdad sobre los desaparecidos en Colombia, esto es, la posible vuelta a la victimización a través dela amenaza. Entonces, los medios funcionan en estos casos como escudo de protección. Es el trabajo periodístico el que da cuenta de las intenciones de los actores armados de acallar y acabar con el movimiento social de Madres, que ha sido capaz de poner en evidencia las atrocidades de las que han sido víctimas un sinnúmero de personas. El eco de las amenazas, al ser publicadas en los medios de comunicación, ganan lugar entre la ciudadanía que aprecia y valora el trabajo de las Madres, generando alerta pública y vigilancia.

Estas publicaciones también sacan a la luz el hecho de que el coraje no es solo cuestión de hombres, como lo hacen creer los actores violentos. Un ejemplo de lo anterior es la publicación del periódico El Colombiano del 13 de enero de 2011, donde se informa sobre las amenazas contra Teresita Gaviria. El texto informa sobre el envío de un sufragio marcado con su nombre y varias llamadas intimidantes que hacen parte de un cúmulo de amenazas. Ella subraya que desde hace algún tiempo viene siendo intimidada por hombres que se presentan en los plantones, que llegan hasta la oficina. Después de las publicaciones en medios, estas amenazas fueron rechazadas por La Comisión Nacional de Reparación y Reconciliación (CNRR), la Misión de Apoyo al Proceso de Paz de la OEA (MAPP-OEA) y el Centro de Fe y Cultura, quienes pidieron a las autoridades que se encuentren a los responsables de estos hechos. 
En resumen, puede afirmarse que hay una gran complementariedad en la relación entre medios de comunicación y movimientos sociales vinculados a la defensa de los Derechos Humanos, que propician una imagen de responsabilidad y compromiso social de los media. El ejercicio periodístico desde el enfoque de construcción de lo público-político ha permitido la legitimidad social de las Madres de la Candelaria, derivada de la comprensión de las razones que impulsan sus acciones colectivas, desde una visión compleja de la realidad. Este ejercicio posibilita hacerle frente a una perspectiva reduccionista y negativa de las víctimas-mujeres desplazadas, bastante común entre los medios masivos. Sin embargo, es de destacar que la visibilidad de la desaparición forzada por los medios de comunicación ha sido en Colombia producto de un largo recorrido de los movimientos sociales por lograr que los medios más destacados publicaran sus acciones, hicieran eco de sus demandas e informaran en formatos que rebasan lo noticioso, dejando en el pasado la decisión de ocultar lo que hoy es inocultable. En la actualidad, las Madres de la Candelaria gozan de un gran reconocimiento entre las instituciones del Estado, y se mantienen dentro de la agenda pública de medios masivos y alternativos.

\section{Referencias bibliográficas}

Barbero, J. M. (1993). La comunicación en las transformaciones del campo cultural. Revista Alteridades, 3(5), 56-98.

Borja, J. y Muxí, Z. (2000). Espacio público, ciudad y ciudadanía. Barcelona. Extraído el 16 de julio de 2012, desde: http://pensarcontemporaneo.files.wordpress. com/2009/06/el-espacio-publico-ciudad-y-ciudadania-jordi-borja.pdf

Centro Nacional de Memoria Histórica (2013). ¡Basta ya! Colombia: memorias de guerra y dignidad. Grupo de Memoria Histórica CNMH y Departamento Administrativo para la Prosperidad Social. Extraído el 15 de septiembre de 2013, desde: http://www.centrodememoriahistorica.gov.co/micrositios/ informeGeneral/

Garretón, M. (1998). ¿En qué sociedad vivi(re)mos?. Tipos societales y desarrollo en el cambio de siglo. Estudios Sociales, 14. Obtenido el 8 de marzo de 2012, desde: http://www.insumisos.com/lecturasinsumisas/tipos\%20 societales\%20de\%20Garreton.pdf

Haugaard, L. y Nicholls, K. (2010). Rompiendo el Silencio. En búsqueda de los Desaparecidos en Colombia. Washington D.C.: Grupo de Trabajo sobre Asuntos Latinoamericanos, Oficina de los Estados Unidos sobre Colombia.

Lecaros, M. J. (2003). Una mirada ética en torno al pluralismo, la objetividad y la información. En Veracidad y Objetividad. Desafíos Éticos en la Sociedad de la Información (pp. 57-80). Obtenido el 25 de octubre de 2012, desde: http:// eprints.ucm.es/6127/1/definitivo.pdf 
Miralles, A. M. (2009). Periodismo público en la gestión del riesgo. Perú: Comunidad Andina.

Miralles, A. M. (2002). Periodismo, Opinión Pública y Agenda Ciudadana. Bogotá: Norma.

Riaño, P. (2002). Las rutas narrativas de los miedos: sujetos, cuerpos, memorias. En El miedo. Reflexiones sobre su dimensión social y cultural (pp. 85-106). Medellín: Corporación Región.

Rovira-Sancho. G. (2013). Activismo mediático y criminalización de la protesta: medios y movimientos sociales en México. Convergencia, Revista de Ciencias Sociales, 20(61), 1405-1435.

Truñó, M. (2007). No solo víctimas: mujeres en el lugar social de víctima y relaciones de género. Otro Derecho, 36, 129-147.

\section{Entrevistas}

Gaviria, Teresita, [entrevista] 2013, líder del movimiento social: Asociación Caminos de Esperanza Madres de la Candelaria. Por: Alba Shirley Tamayo Arango. Medellín, Antioquia.

Gaviria, Teresita, [entrevista] 2012, líder del movimiento social: Asociación Caminos de Esperanza Madres de la Candelaria. Por: Alba Shirley Tamayo Arango. Medellín, Antioquia.

Correa, Luz Patricia, [entrevista] (2013), directora de la Unidad de Atención y Reparación a Víctimas del municipio de Medellín. Por: Alba Shirley Tamayo Arango. Medellín, Antioquia.

Higuita, Juan Carlos, [entrevista] 2013, periodista Radio Cadena Nacional de Colombia RCN. Por: Alba Shirley Tamayo Arango Medellín, Antioquia. 